\title{
Depression Survivors Among Emerging Adults: Their Healing Journey
}

\author{
Pui Wei Zhe \& Jamayah Saili* \\ Faculty of Cognitive Sciences and Human Development, \\ Universiti Malaysia Sarawak, 94300 Kota Samarahan, Sarawak, Malaysia
}

\begin{abstract}
This qualitative study explored the healing process of depression survivors among emerging adults with effective coping strategies utilised by them. A semi-structured interview was conducted on participants aged between 18-28 years old. A theme narrating the experience of the depression survivors were identified: The journey of healing - Crawling out of the quicksand. The survivors emphasised that to achieve healing, everything starts from within the self, and they had been putting in a lot of their extra efforts in helping themselves heal. They all went beyond recovery, where their efforts illustrated their focus on healing, thriving, and achieving optimal well-being upon recovery. Significantly, the relevance and applicability of the building blocks of Seligman's PERMA model of well-being towards those efforts taken were revealed in the study.
\end{abstract}

Keywords: depression survivors, the healing process, emerging adults, challenges, coping strategies, optimal well-being

ARTICLE INFO

Email address: sjamayah@unimas.my (Jamayah Saili)

*Corresponding author https://doi.org/10.33736/jcshd.3863.2021

e-ISSN: 2550-1623

Manuscript received: 27 August 2021; Accepted: 20 September 2021; Date of publication: 25 September 2021

Copyright: This is an open-access article distributed under the terms of the CC-BY-NC-SA (Creative Commons Attribution-NonCommercial-ShareAlike 4.0 International License), which permits unrestricted use, distribution, and reproduction in any medium, for non-commercial purposes, provided the original work of the author(s) is properly cited. 


\section{INTRODUCTION}

Major Depressive Disorder (MDD) is the most common mental illness affecting an estimated 2.3 million people in Malaysia. Accounting for the highest prevalence of depression, one in four (25\%) emerging adults between 18 to 25 years old suffer from a depression episode in Malaysia (Mukhtar \& Oei as cited in Chan, Hutagalung, \& Lau, 2017).

Curing depression is significantly different from healing. While current treatments emphasise curing the illness, symptoms, and deficits (Chowdhury, 2019), healing, on the other hand, focuses on well-being by emphasising on strengths instead of weaknesses, creating the desired fortunes instead of repairing the uncontrollable unfortunates and pushing one's life up to "amazing" instead of just struggling to be "normal" (Peterson as cited in Ackerman, 2018). The difference is perfectly reflected through the notions of "I am still sick." VS "I am still healing." (Gilliban, 2019). Undeniably, healing comes from within.

Nevertheless, to date, psychological well-being is not included among the general principles of Malaysia's Clinical Practice Guidelines for MDD (Malaysian Health Technology Assessment Section [MaHTAS], 2019). The risk of relapse is always there. The overriding of the chronic and negative forms of depression have also caused chances of thriving after depression to be neglected. Therefore, instead of merely exploring the recovery process (which involved curing all the depressive symptoms), this study attempted to explore the healing process of the survivors of depression alongside the coping strategies that enabled them to combat depressive challenges and thrived as a survivor of depression.

\subsection{Curing (recovering) VS Healing (thriving)}

According to Lerner (2015), professionals give curing, whereas healing comes from within. Besides eliminating symptoms, healing is an integrative process that includes physical, mental, spiritual, emotional, and well-being (Mooney, n.d.). It involves non-stop rediscovery of the meaning to be alive. It not only represents being at the peak of "spiritual experience at all time but, more importantly, being able to live along with ongoing life challenges, struggles and hardships as well as joys in a way we feel whole.

Recently, the focus on symptoms and illnesses has shifted towards strengths and resources (Schrank, Brownell, Tylee, \& Slade, 2014). Hence, recovery from mental illness extends to how people can re-engage in their lives, rooting from their strengths and goals, discovering meaning and purposes through putting together and regaining a valued identity social role (thriving). It clearly shows that the movement of recovery is favourably congruent with positive psychology.

\subsection{Determinants of Well-Being in Depressive Patients}

Age and level of social support are determinants that correlate positively to all the quality of life (QoL) domains, including the psychological well-being of the depressive outpatients (Shumye, 
Belayneh \& Mengistu, 2019). As patients age, they become more in a state of acceptance towards their lives and about themselves (Peltzer \& Phaswana-Mafuya as cited in Shumye, Belayneh \& Mengistu, 2019). People with a better level of social support will have better social relationships, better self-image, more attached engagement to the community and have somebody close to share their happy and distressing moments (Shumye, Belayneh \& Mengistu, 2019). On the other hand, psychological well-being aspects of QoL are diminished among those patients with perceived stigma because of their depressive states (Shumye, Belayneh and Mengistu, 2019).

\subsection{Well-being and Healing Process}

Depression is conceptualised with overriding negatives, including negative cognitions, negative feelings, and negative moods (Sin, Delta Porta, \& Lyubomirsky, 2010), leading current treatments to focus on reducing and eliminating these negatives neglecting the importance of building and fostering the positives instead.

"Positive psychology is another arrow in the quiver of public policy and psychology through which we can raise well-being above zero." (Seligman,2002). PERMA theory of well-being proposed by Seligman was intended to answer the essential question involving positive psychology: "What is human flourishing and what enables it?" (Positive Psychology Centre, n.d.). According to Seligman, five fundamental building blocks enable flourishing, thus makes up the theory of wellbeing: Positive Emotion, Engagement, Relationship, Meaning and Accomplishment.

Several studies reported that the PERMA model is associated with recovery from depression, although research on this is still limited. An increase in positive emotions among depressed individuals had resulted in speedy recovery from enhanced broad-minded coping skills (Fredrickson \& Joiner, 2002). It acted as a buffer that prevents relapses (Fava \& Ruini, 2003). According to the broaden-and-build theory proposed by Fredrickson (as cited in Sin, Delta Porta, \& Lyubomirsky, 2010), positive emotions are essential in broadening mindsets, thinking and attention, enabling one to generate new ideas and behaviours and eventually lead to fostering long term personal resources. It is why, among the depressed, milder depression and a greater chance of recovery are found among those with greater approach-oriented motivation (Kasch, Rottenberg, Arnow, \& Gotlib as cited in Sin, Delta Porta, \& Lyubomirsky, 2010).

According to Seligman, Steen, Park, \& Peterson (as cited in South Australian Health \& Medical Research Institute [SAHMRI], n.d.), individuals with solid engagement who make use of their strengths in new and diverse ways every day for a week were found to be happier and less depressed six months later. In terms of relationships, individuals with remarkable mental illness revealed that social support from family and friends is the leading factor that contributed to their recovery (Cohen as cited in SAHMRI, n.d.). Besides, individuals who managed to define meaning after an adverse life event are more likely to return to the initial level of functioning more positively (King, Hicks, Krull \& Del Gaiso as cited in SAHMRI, n.d.). As recovery from depression takes time, a sense of accomplishment is vital for patients to stay confident and determined (Seligman \& Schulman as cited in SAHMRI, n.d.). However, how each of these building blocks plays its role in the well-being of depressed emerging adults is still less known. 
Maintaining and thriving for psychological well-being after recovering from depression is crucial, given that depression is recurrent. Thankfully, Rottenberg et al. (2019) had reported that nearly $10 \%$ of those who were depressed managed to attain optimal well-being ten years later. Those depressed individuals with a higher level of well-being at the initial stage of study are found to have a greater chance of thriving (30\% probability) after recovery. To date, the pattern of psychological well-being of depression survivors has yet to be well-explored in the context of Malaysia's culture, particularly among emerging adults.

\subsection{Coping strategies}

Grieken, Kirkenier, Koeter and Schene (2014) reported that from the depressive patients 'point of view, there are three meta-clusters of coping strategies in enduring depression (residual symptoms of depression), including focusing on depression (active coping), active lifestyle (active self-care, planning and structuring as well as leisure activities) and engagement in daily social life (social engagement and work-related activities).

Another study had revealed that guilt denial and reaction control are two adaptive and desirable coping strategies for depressive patients (Holubova et al., 2018). Those depressed who practise guilt denial tend to highlight and remind themselves that they are not responsible for the situation, and thus, they should not be blamed. In comparison, those patients who utilised reaction control put effort into securing and maintaining control of their response. Additionally, research on depressed emerging adults revealed that social support and networks could help them alleviate emotional distress (Hernáez, Maicas, Digiacomo, \& Ariste, 2016).

\subsection{Study rationale}

The present study aimed to explore the healing process of depression survivors among emerging adults by examining how these survivors put in their efforts (apart from seeking professional help) to successfully heal from depression, hoping to raise the awareness among other patients that healing comes from within. This study focuses on uncovering the well-being of depression survivors rather than the elimination of the symptoms. It may signify the need for a change in basic assumptions in viewing the psychopathology outcomes and spark a new study interest in strategies to increase the chances of thriving after depression. A qualitative approach is used, richer and more in-depth knowledge of what made healing successful among these depression survivors could be obtained, bringing positive changes in the lives of the other emerging adults with depression in the Malaysian context.

\section{METHOD}

\subsection{Participants}

The study targeted three emerging adult depression survivors. Inclusion criteria include (1) aged between 18 - 25 years old; (2) had a clinical diagnosis of major depressive disorder (MDD); (3) had recovered or become an outpatient who experienced life satisfaction or happiness every day 
for the previous month and with a full year without experiencing depressive symptoms; (4) had been back to normal daily functioning (work or study). The exclusion criteria were (1) still suffer from severe depression and (2) have suicidal intent (to avoid adverse effects that interview process may pose to their illness). Purposive sampling and snowball sampling were applied in recruiting participants.

Among the participants, two were Chinese, and one was Malay (Table 1). Nick, 28 years old, was the eldest and was also the only one who already had his own's career and family. He started having depression at age 23 years old, and schizophrenia bugged in about two years later. On the other hand, Ling and Mira were secondary and university students, respectively. Both Nick and Ling were staying in Johor, whereas Mira stayed in Sarawak.

Table 1. Demographic Data of Depression Survivors among Emerging Adults.

\begin{tabular}{ccccc}
\hline NO. & Name & Age & Race & Occupation \\
\hline $\mathbf{1}$ & Nick & 28 & Chinese & Businessman \\
$\mathbf{2}$ & Ling & 19 & Chinese & Student \\
$\mathbf{3}$ & Mira & 22 & Malay & Student
\end{tabular}

\subsection{Design}

A qualitative approach is best suited for this study because of its potential to maintain the complexity of human behaviours and allow the researcher to conduct a detailed exploration of the participants. The uniqueness and idiographic of these depression survivors were richly extracted. As qualitative research is interpretative, the researcher's beliefs, biases and judgements would affect the accuracy of data analysis (Strauss \& Corbin, 1998). Therefore, to minimise this, the transcript was reviewed by a $3^{\text {rd }}$ party (supervisor) to identify the researcher's preferences for specific evidence and explanations, detect blind spots and omissions, and assess the researcher's judgements throughout the study so that findings were relevant and bias-free.

A semi-structured interview was employed to obtain information beyond observations such as thoughts, emotions, and intentions. Interview sessions were carried out according to the interview protocol (guided interview questions), serving as a guideline throughout the interview.

\subsection{Data Collection Procedure}

The interview started with building a good rapport with the participants through self-introduction and small talks. The participants were then briefed on the research purpose, procedures, significance of the study, with the informed consent clauses read out to them. Recordings only started after their permissions were obtained.

Leading questions that could affect the accuracy of the information given by the participants were avoided. A face-to-face interview was conducted to capture verbal and non-verbal cues, including body language and facial expression. It helped recognise their emotions and sensing the 
enthusiasm or discomfort towards the questions asked. Lastly, the researcher then proceeded to obtain the demographic details of the participants. The reason to ask the demographic questions at the very last was to ensure that participants 'attention and focus were optimal while answering research-objectives-related questions, which were thought to be more challenging. Each interview session lasted for 45 minutes to 1 hour.

\subsection{Data Analysis}

Thematic analysis was the primary tool used for the data analysis, which involved identifying, analysing, and recognising the patterns of the transcribed data (Braun \& Clarke, 2006). These patterns would then be used to identify emerging themes. Therefore, it is crucial to have sound judgements in identifying the emerging themes because these would represent the overall patterns of the participants 'responses in relevance to the research objectives and questions. The thematic analysis was applied in this research because it provided great flexibility (Nowell, Norris, White, $\&$ Moules, 2017). The researcher got to organise the data into various categories according to the patterns recognised.

\section{FINDINGS}

The findings ideally present stories and exhibit how the three participants progressed through their healing journey through an emerging theme (Table 2).

\subsection{The Journey of Healing - Crawling Out of The Quicksand}

To succeed in the journey of healing from depression, the participants knew that they must start getting real and take actions beyond merely receiving professional help. They believed that everything must start from within self by first rebuilding their lost sense of self and cultivating greater self-acceptance. Besides, active coping, active lifestyle, engagement in everyday social life and reframing thought patterns are all reflected in their effort of recovering.

\subsubsection{Sub-theme 1: Rebuilding the Sense of Self - Everything Starts from Within Self}

Determination and Motivation. Based on the interview, all the participants emphasised that their efforts are the absolute prerequisite to heal. They all reflected that determination and motivation are a lot more critical than merely seeing doctors and having medication.

“...Seeing doctor is one matter, more importantly you have to rely on your own. How determined and motivated you are. Doctors and medicine temporarily suppress your thoughts only. From this moment onwards, everything depends on how you think. After you have the medicine, how will you think of recovering, for what sake you want to recover... Confidence is not something that others can give you, you have to build-up on your own..." (Nick)

Mira reported that she constantly put in the effort to remind herself to persevere in fighting depression. She promised her psychologist, which served as a reminder and motivation for her to keep going. 
"...this illness is not something that is going to stop me from exploring things. I would just accept it as it is. Ineed to have determination to recover...It makes me want to keep going until I feel like I'm already fully recovered from this when I think I have come a long way to give up on it...I usually remind myself about how far my progression has been...I think my own role is more important than professional help..." (Mira)

Self-efficacy and Confidence. All the participants emphasised that believing in self was one of the most crucial elements that kept them determined and motivated enough to persevere in the challenging recovery route.

“... Confidence is a very basic prerequisite... because my confidence is back, and I am able to face and talk to a person... Must believe that you can do it. Even if you don't have family or friends who care or concern about you, it is all ok although it'll be harder, because everything starts from yourselves..." (Nick)

"...if you are unsatisfied with anything in our life, change it... I look back at my old photos and videos... I saw how happy I was compared to now...it motivates me to be as happy as I used to... Instead of letting the old self to defeat me, I am letting my old self to guide me as a reference to live the better version of myself. It was a source of confidence that I have..." (Mira) 
Table 2. Theme, subthemes, and categories

\begin{tabular}{|c|c|c|}
\hline Theme & Subtheme & Categories \\
\hline \multirow{13}{*}{$\begin{array}{l}\text { The Journey Of Healing: } \\
\text { Crawling Out Of The Quicksand }\end{array}$} & \multirow{2}{*}{$\begin{array}{l}\text { Rebuilding the sense of self - } \\
\text { Everything starts from within self }\end{array}$} & Determination and motivation \\
\hline & & Self-efficacy and confidence \\
\hline & \multirow{2}{*}{$\begin{array}{l}\text { Greater self-acceptance of who } \\
\text { they were/are }\end{array}$} & Perception towards self as depressed \\
\hline & & Embracing own's strength and weakness \\
\hline & \multirow[t]{2}{*}{ Active coping } & Commitment to professional help \\
\hline & & $\begin{array}{l}\text { Acknowledging and dealing with depressive } \\
\text { symptoms effectively }\end{array}$ \\
\hline & \multirow[t]{2}{*}{ Active lifestyle } & Planning and structuring approach goals \\
\hline & & Leisure activities \\
\hline & \multirow{3}{*}{$\begin{array}{l}\text { Engagement in everyday social } \\
\text { life }\end{array}$} & Seeking family support as sustenance \\
\hline & & Reaching out to non-kin companions \\
\hline & & Slowly engaging in work-related activities \\
\hline & \multirow{2}{*}{$\begin{array}{l}\text { Reframing thought patterns - } \\
\text { Whole shift of attitude and perspectives }\end{array}$} & Gratitude and optimism \\
\hline & & Sense of accomplishment \\
\hline
\end{tabular}


However, Ling was not as confident as Nick and Mira. She still had doubts about how well she could recover. Nevertheless, she still believed that she would surely make improvements as long as she was determined enough.

“...I found it really difficult to find my confidence back, although I actually managed to make some improvements... I didn't dare to imagine to fully recover until I am capable of chasing my dream... But I try my best to remind myself to believe that I can get better..." (Ling)

\subsubsection{Sub-theme 2: Greater Self-Acceptance of Who They Were/Are}

Perception towards Self as Depressed. Though it was harsh, the participants' responses reflected that they could finally accept themselves as individuals with depression. More importantly, all of them neither discriminate themselves from others nor self-blame for suffering from depression.

“...I feel that actually everyone has this illness, just the matter of serious or not, and whether they can control their own emotions well... They still have the ability to control their own emotion, but at that time, we couldn't manage to control our own emotions and that's why we became like this, we become afraid to be seen by others..." (Nick)

For Mira, she perceived herself suffering from depression as a process of learning to understand herself more. She also perceived having depression as an opportunity of improving her self's capability to help.

"...I could use the method that I learnt during my therapy session to help my friends who are also in the same position or when they are feeling down or needed advice. If I don't go through this, I wouldn't learn more about myself or people around me...” (Mira)

Embracing own's strengths and weaknesses. The participants took the courage to acknowledge and accept their own's strengths and weaknesses. They were able to forgive their own' past mistakes. It was reflected when they claimed to have realised that the pursuit of perfection was in vain.

“...We should calmly accept our own weaknesses instead of just thinking to keep it from others. As you calmly accept every bad side of yours, as long as you are still alive, you can always change...step-by-step, slowly learn to acknowledge the bad sides in you, don't discriminate yourselves. I had discriminated myself and that lead me to depression..." (Nick)

\subsubsection{Sub-theme 3: Active Coping}

Instead of avoiding, all the participants acknowledged and always bore in mind that they must take the depressive signals seriously. Commitment to Professional Help. The participants took the initiative to ensure strict commitment to both medication and psychotherapy as their professional help. They had been keeping up with long-term professional support to achieve optimal effectiveness of treatment. Mira made sure to reach out to every possible means of professional 
help and made full use of the resources available, including the government mental hospital and university counselling unit.

Acknowledging and dealing with depressive symptoms effectively. Besides committing to professional help, the participants had put in their effort in helping themselves to recover from depression. Nick took the initiative to figure out and understand why it caused him to "fall sick". He was aware of the possible factors that led him to fall into the bandwagon of depression.

“...when situations come, we don't dare to accept them. We hide them deep in our heart and keep accumulating, keep depressing and ended up in depression...I had discriminated myself and that lead me to suffer from depression and schizophrenia..." (Nick)

Mira took the initiative to observe, study, and understand her depression and anxiety symptoms and pushed herself to overcome those symptoms by counteracting them.

"...I don't like socialising with people, but I try going out more and would actually make some time for my friends... Instead of remembering embarrassing things that happened to me, I try to remember embarrassing things that happen to others. As I tried, I couldn't remember any of that. So probably others wouldn't remember embarrassing things about me too... Every time I start to think things like that (suicide), I will usually try to distract myself talking to someone about it..." (Mira)

On the other hand, Ling was determined and motivated to cope with the symptoms she was experiencing for both depression and schizophrenia. She prioritised her own's mental health over her education prospects. Achieving recovery is always her main goal until now.

“...I try to make myself not to listen to those voices. I will control myself and not to bother those voices... The voices seem to be less when I am singing... recovering from my condition now is also my goal..." (Ling)

\subsubsection{Sub-theme 4: Active Lifestyle}

Planning and Structuring Approach Goals. It was another crucial element that was reflected in participants while tackling their depression. Nick adjusted his activity schedule and always ensured having enough rest to avoid exhaustion through over-exertion. Ling and Mira had a unique way of doing planning and structure. They made an effort to proactively set realistic short-term goals and make plans for the future.

“...Be healthier, dress up, find your confidence back ...I would do some simple tasks that I am competent in first instead of those complicated ones, slowly become more confident... set a schedule to plan your activities in daily lives. Then have rest. Let yourself relax, put behind all the unnecessary thoughts, let go all the worries and rest your mind..." (Nick)

Leisure Activities. Carrying out leisure activities is related to engaging in depression-independent leisure activities. All participants agreed that they felt time "flies by" very fast while carrying out leisure activities. Both Nick and Mira personally thought that exercising was crucial and played a big part in helping them recover. 
“...Most importantly is exercise...you need a lot of energy and spirit to face all these kinds of problems (sickness). It helps to get rid of all the negativities in you... Keep doing and let your body reenergise, then you will have the pushing force, the spirit and positive energy to face it. Or else, you will feel very lazy, down, totally unable to bestir... Very happy. I will have very good mood and will not feel irritated or think of anything..." (Nick)

Mira indirectly boosted her confidence by distracting herself and socialising with people. It reflected not only Mira's effort in combatting her depressive symptoms but also active self-care. On the other hand, Ling made an effort to pursue on own's hobbies and even took the initiative to uncover their own's unknown talent by taking up piano and vocal classes. These made her feels great, especially when she could master the skills.

\subsubsection{Sub-theme 5: Engagement in everyday social life}

Participants had perceived social engagement as a potent tool that helped them recover from depression. Seeking family support as sustenance. To the participants, the family were the first ones they reached out for help. All of them strongly agreed that family support had become the pivot motivator that pushed them towards recovery.

"...people surrounding should be more considerate to this person, concern him, encourage him, let him know that even if he could not accomplish anything, he still has them with him...just ask him to do well, stay alive well, live well, then it is all enough...not asking him to find a job, it's not about giving him these indirect pressures..." (Nick)

Ling also took the courage to tell her family about experiencing the symptoms. On top of that, family encouragement and suggestion led her to explore the self. She had also tried hard to fight depressive symptoms by engaging in deep conversation with family.

"...I told them those voices kept annoying and disturbing me... At first it was my mom who suggested me to take up piano lesson, of course I am interested. I chat with my family, my parents and siblings... Feel glad and better mood when chatting because there are less voices when I am chatting..." (Ling)

Unfortunately, unlike Nick and Ling, Mira's family did not play an essential role in helping her recover. Instead, her family issues played a part in causing her to have depression, and she always tried avoiding quarrels with her family. However, Mira has a remarkably close relationship with her mother. She mentioned that contributing to and supporting her mother is a sustenance that is more powerful than receiving family support.

“...She trusts me. And she also needs someone to hear her... I feel bad for her. I'm trying to be a good daughter to her...It kind of motivates me to get back to doctors. I want to get a decent job, so I'm able to help her financially and support her..." (Mira)

Reaching out to Non-Kin Companions. The participants also reached out to non-kin companions whom they trust, such as friends and partners. For Nick, encouragement from friends served as a great push, just like a helping rope pulling him out. Social support by friends helped him to be 
more attached to the community. Mira also took the initiative to reach out to her friends whenever she had problems. It helped ease her burden of keeping problems to herself and feel worth among her friends. Besides having good friends, Mira had expressed gratefully that her boyfriend had been the pillar that brought her towards the path of recovery to healing. As a relationship is not one-sided, Mira tried to maintain her relationship with her boyfriend without making depression excuses not giving.

However, Ling did not tell her friends regarding her condition as she was afraid that it would be a burden for them if they knew her condition.

“...if I tell, it will add on their burden, maybe like they will keep thinking how they can help me to solve the problems... That's why it become harder for me to make friends because I am unwilling to share my thoughts or worry with them..." (Ling)

Slowly engaging in work-related activities. All participants agreed that slowly engaging in work or study-related activities helped them occupy themselves with positivity while reattaching them to reality. Nick pushed himself to slowly be involved in volunteering work, mentioning that this had helped him reattach with the community he had long detached from due to depression.

“... Whenever I go to the temple, they will keep encouraging me and this helped me get better... we couldn't be alone quietly because when you are alone and the more you don't get in touch with others, you will slowly detach from the world and ended up become even more negative... meet those with positivity who will give you positive words of encouragement, ignore the negatives. Buddhism had helped me a lot..." (Nick)

Mira reported that even though Human Resource Development (HRD) was not the course she wanted, she took the effort to learn about it through lectures slowly. As she slowly explored her career path in future, she aimed to become a HR manager to change the stigmatised perspectives towards employees with mental health issues. She started to work towards her goal slowly.

\subsubsection{Sub-theme 6- Reframing thought patterns: Whole shift of attitude and perspectives}

Although the participants agreed that reframing thought patterns were complex, their impact was so significant that they felt a whole shift of attitude and perspectives, bringing them towards the opposite side of the negative thoughts they were so used to before.

Gratitude and Optimism. Not only that the participants learn about cherishing loved ones, but most importantly, cherishing oneself. They demonstrated optimism in confronting and accepting themselves as someone who was depressed. They managed to find blessings in the disguise of depression.

"...there are still many things that are worth doing and cherishing. I can eat, I can walk, I can do whatever I want, there are a lot of things I can help with. I can help my children, my wife, my family... Isn't this the best way of staying alive?... To overcome, you need to have a belief, you find back what you want to cherish the most..." (Nick) 
“...To cherish life and time more. Because I was depressed and kept hearing voices, it delayed me from doing things. Every minute and second had become more precious for me...I am very thankful that my family still loves me and takes care of me unconditionally..." (Ling)

"...I start to love myself and I feel happy for my life... it helps me to see on the positive side, by not being negative all the time... Healing from depression is when I can be happy without depending my happiness on someone else and when I can accept myself and love myself..." (Mira)

Sense of accomplishment. The participants were proud of what they managed to accomplish, especially during their suffering of depression, more so that they managed to stay alive when depression pushed them to the edge of death.

“...I am still alive. At least I am still alive. This is my biggest accomplishment. Because I am still alive, I still can accomplish more things... Chunk the big target into a puzzle, small pieces, then I start accomplishing piece by piece and slowly a complete picture will emerge... Every small piece/part is your accomplishment..." (Nick)

"...my biggest accomplishment is that I start to love myself and feel happy for my life... I am able to be happy without depending my happiness on other... it makes me proud of myself because it is a huge difference to compare the person who I am today to the person who I was ...I'm able to control myself from suicidal thoughts and even self-harm." (Mira)

\section{DISCUSSION}

The present study explored the healing process of depression survivors among emerging adults, alongside coping strategies utilised by them. The study revealed how the participants' efforts had helped them heal, survive, and thrive through depression. This paper spells out how they continuously helped themselves progress towards healing. All participants believed that "everything starts from within self", both in taking the first step and continuously putting in own's efforts throughout the whole healing process. Beyond merely fighting depressive symptoms, their efforts reflected reengagement to their lives, rooting from their strengths and goals, and discovering meaning and purposes through putting together and regaining a valued identity and social roles.

Self-criticism resulting from a deficiency in developing a sense of self can lead to elevated symptom severity in MDD (Kopala-Sibley \& Zuroff, 2020). The participants took up their responsibility to recover with firm determination and motivation to rebuild a sense of self. It supports findings by Holubova et al. (2018), stating that those depressed who showed a better outcome in psychotherapeutic treatment were the ones with a higher level of autonomous motivation. The participants also tried hard to enhance their self-efficacy and confidence in seeking help and ensuring commitment to persevere through the healing journey. One participant took the initiative to look back at her old photos and reminded herself of how happy she was, serving as a source of confidence that motivated her to keep fighting. It proved that self-esteem (confidence) is a critical aspect of the sense of self and is related to depression (Kopala-Sibley \& Zuroff, 2020). 
In making sense of their experiences of depression, the participants adopted greater selfacceptance by first changing their perception of themselves as depressed, which fostered their well-being and recovery. It supports Shumye's, Belayneh's and Mengistu's (2019) study reporting that diminished psychological well-being was evident among patients with perceived stigma towards their own's depressive status. The participants practised guilt denial by reminding themselves that they are not responsible for the situation, and thus, they should not be blamed for it (Holubovaet al., 2018). Besides, they also embraced their own's strengths and weaknesses. Not only they appreciated their own's strengths, but they also took the courage to acknowledge and accept their weaknesses. They reported that this enabled them to learn from mistakes and change, making them feel authentic when embracing the "real" them (Wood, Linley, Maltby, Kashdan, \& Hurling as cited in SAHMRI, n.d.). In general, their perception towards self as depressed and embracing their own's strengths and weaknesses had led them to accept themselves more wholeheartedly, resulting in serenity (Ackerman, 2020)

The participants also practised active coping, active lifestyle, and engagement in social life. They put in significant effort to ensure strict commitment to long-term professional help (Grieken, Kirkenier, Koeter \& Schene, 2014) and effectively acknowledge and deal with their depressive symptoms. They were aware that they must take the depression signals seriously and avoid them (Grieken, Kirkenier, Koeter \& Schene, 2014). Besides, they also practised active lifestyles by planning and structuring approach goals instead of avoidance goals, instilling a feeling of satisfaction and hope in them. They had been adjusting their schedules to ensure enough rest, proactively setting realistic short-term goals, and making future plans (Grieken, Kirkenier, Koeter \& Schene, 2014). They also engaged in depression-independent leisure activities, including exercising, working out, playing musical instruments, and singing. These made them feel great, and that time passed very quickly. It supports the findings that individuals who use their strengths in new, more frequent, and diverse ways were happier and less depressed six months later (Seligman, Steen, Park, \& Peterson as cited SAHMRI, n.d.).

Additionally, the participants ensured social engagement by seeking family support as sustenance and reaching out to non-kin companions, including friends and partners. While these were the pivot motivators that pushed them towards recovery, performing kind acts on others enhanced well-being (Positive Psychology Centre, n.d). One participant (Mira) uniquely reported supporting her mother was more powerful sustenance than receiving family support. It supports Cohen's (as cited in SAHMRI, n.d.) findings stating that connection of social relationships leads to lesser mental illnesses such as depression and is the best remedy to the downturns in life (Positive Psychology Centre, n.d).

Additionally, engaging in work-related activities kept the participants occupied with positivity and enabled them to reattach reality. Coping strategies that are opposite to avoidance behaviours manifested in the clinical pattern of depression are said to be helpful (Trew as cited in Grieken, Kirkenier, Koeter and Schene, 2014). The participants reported a sense of satisfaction when accomplishing tasks in work-related activities. While Grieken, Kirkenier, Koeter and Schene (2014) reported that active coping, active lifestyle, and engagement in social life were coping strategies utilised in the partial remission stage, the participants in the present study started 
practising these strategies much earlier when their conditions were still severe. It may implicate that these strategies can be helpful for all depression patients regardless of their severity.

Furthermore, the participants' efforts also involved reframing thought patterns, whereby gratitude and optimism were reflected in their responses. Upon being optimistic in confronting and accepting themselves as someone with depression, they managed to find blessings in the disguise of depression. Studies showed that gratitude interventions are associated with well-being, satisfaction in life, happiness, and positive effects, which helps in decreasing depressive symptoms (Dickens as cited in Allen, 2016). Reframing thought patterns had contributed to a sense of accomplishment in the participants through self-gratitude. As the participants appreciated that every small step taken was an accomplishment, they slowly became more confident and did not forget to celebrate every achievement they got (Bennett, 2018). The tremendous confidence and accomplishment they were most proud of where that they did not commit suicide when they had no choice but to kill themselves. It supports Ledwidge (1980) findings, where self-esteem and confidence promote a sense of accomplishment that helps combat helplessness and desensitises depression.

\section{The Applicability and Relevance of PERMA Model in Healing Process}

In the present study, the efforts taken by all the participants had undeniably demonstrated a multidimensional aspect of well-being. Positive and negative feelings are two independent events (Watson \& Tellegen, cited in Sin, Delta Porta, \& Lyubomirsky, 2010). The adverse effects are not equivalent to the absence of the positive ones and vice versa. Pain and stress from the never "linear" healing journey had intermingled with positivity, flourishing, eventually building a sense of resilience, and finally thriving in the face of adversity despite depression. The participants' efforts had powerfully demonstrated the applicability and relevance of Seligman's PERMA model of well-being and illustrated the interrelatedness between each building block.

Positive emotions refer to the feeling of joy and happiness that the participants had experienced, which involves how well one can remain optimistic to view one's past, present, and future from a constructive perspective (Positive Psychology Centre, n.d.). In the effort of rebuilding a sense of self and cultivating greater self-acceptance, the participants had practised positive emotions of serenity (a peaceful and calm feeling of acceptance of self), self-efficacy and confidence (an emotion that is made up of a keen sense of believing in self and self-esteem). They also possessed gratitude and optimism through reframing thought patterns. Like Ackerman's (2020) research stating that positive emotions promote effective coping, the participants managed to impose active coping and ensured continuous efforts in dealing with residual symptoms to achieve thriving. It supports the broaden-and-build theory proposed by Fredrickson (as cited in Sin, Delta Porta, \& Lyubomirsky, 2010). Their positive emotions gave them great approach-oriented motivation to keep fighting depression.

Engagement describes a deep and intense psychological connection to an activity (Khaw \& Kern, 2015). All the participants took the initiative to engage in leisure activities. Their engagement had created an experience of "flow" where they reported becoming so blissfully immersed into what 
they were doing, having their total concentration on the present moment, feeling that selfawareness slowly faded off and time indeed "flies by" (Positive Psychology Centre, n.d.; Pascha, 2019). They also agreed that engaging in active coping helped to foster well-being.

While seeking support from family and non-kin companions by engaging in deep conversations with their loved ones, this also signified fostering and maintaining positive relationships with others, emphasising its importance (Bennett 2018). Positive relationships involve feelings of integrating with the society or community, caring for and being cared for by the people one loves, and satisfaction with one's social network (Khaw \& Kern, 2015). Forming a solid connection with others helps one figure out meaning and purpose in life (Positive Psychology Centre, n.d), especially for Mira. She emphasised that her mother gave her meaningful purpose in life, where her hope to be a good daughter had motivated her to stay on the path of healing. All participants reported affection when they were around their loved ones, proving that positive relationships had fostered positive emotions in them.

Meaning involves having a sense of direction and purpose in life and the feeling of connectedness to something bigger rather than just self (Khaw \& Kern, 2015). The meaningfulness of one's life does not depend on the nature of the life events but is about how one perceives their own experiences in these life events. In the present study, how the participants perceived themselves as depressed and embraced their own's strengths and weaknesses were influenced by how they define meaning in their depression experiences. Besides, how they made sense of their depression experiences also helped in rebuilding a sense of resilience. They turned adverse experiences of depression and painful past experiences into motivation. It is in line with Joseph's and Linley's (as cited in SAHMRI, n.d.) findings. Those who encountered personal growth upon facing adversity were more optimistic and eventually had better positive emotions.

Lastly, setting goals and ambitions in life will push one to thrive for achievements, eventually resulting in the sense of accomplishment within them and flourish (Pascha, 2019). The participants maintained an active lifestyle by planning and structuring for approach goals. They chunked big targets into smaller tasks or achievable short-term realistic goals with their end goals in mind. As they progressed with their plans and managed to achieve one task after another, they developed a profound sense of accomplishment. As they slowly engaged in work-related activities such as volunteering and attending lectures, they reported a sense of satisfaction when they managed to accomplish specific tasks, which gradually boosted their confidence.

\section{IMPLICATIONS}

This study revealed many self-help efforts by the young depression survivors that were way beyond receiving professional help. It implicates and enlarges the patients' capacity in helping themselves to heal by taking up more significant roles and responsibilities in the journey of healing. It amplifies the notion that healing comes from within self (Rankin, 2011) and those treatments will go in vain if the essential mental and emotional well-being elements are absent (Gilliban, 2019). It will acknowledge that healing from depression is never a "linear progress" that matches their normalised recovery expectations. The continuous efforts of the participants in this study 
serve as evidence that signifies the importance of maintaining psychological well-being even after achieving recovery.

The relevance and applicability of every building block of Seligman's PERMA model of wellbeing in helping depressed emerging adults heal and thrive in life were demonstrated in this study. The participants' efforts had proven that PERMA elements of well-being are buildable in depression patients. It signifies a need for a change in thinking in viewing the psychopathology outcomes and sparks a new area of study on determining the strategies to increase the chances of thriving after depression.

\section{LIMITATIONS AND RECOMMENDATIONS}

The limitations faced in this study involve time constraints, sample size, limited access to literature, and methodology. An extended period was consumed for recruiting participants/patients and for the interview sessions and data analysis process (transcribing, coding, and identifying the theme, sub-theme, and categories). The sample size was too small as there was limited access to the target participants who were willing to be interviewed due to concerns about confidentiality. In addition, this study involved participants from the urban area only. Besides, the researcher's own biases could also lead to the subjectivity of the study.

Considering the importance of epiphany illustrated among the participants, exploring triggers of epiphany that lead patients to make the first step into actively fighting depression is highly recommended in future research. Future research shall also explore the applicability of the PERMA model in helping patients recover from depression more in-depth, which may also study the potential of coming out with a new psychotherapy intervention based on the PERMA model.

Besides, establishing a support group within mental hospitals is recommended, where all suitable patients will be automatically assigned as members of the group. To empower the dissemination of successful experiences of overcoming depression, it is recommended that the support group consists of depression survivors and patients, with the professionals as the coordinators. It intends to serve as a platform for the survivors to share how they thrive through depression. Additionally, a mentor-mentee programme can also be implemented within this support group.

Based on the limitations above, future qualitative research studies could consider a more extended period to have more periodic interviews with the participants to obtain a more comprehensive input as they progress through their life. Besides, quantitative research with larger sample size is also recommended to capture a wider variety of patterns in the experience of depression among emerging adults in Malaysia. In addition, it is advisable to expand the research throughout both urban and rural areas to have a more inclusive research result.

\section{REFERENCES}

Ackerman, C. (2018). What is positive psychology \& why is it important? Retrieved from https://positivepsychology.com/what-is-positive-psychology-definition/ 
Ackerman, C. E. (2020). Positive emotions: A list of 26 examples \& definitions in psychology. Retrieved from https://positivepsychology.com/positive-emotions-list-examples-definition-psychology/

American Psychological Association [APA]. (2018). Emerging adulthood. Retrieved from https://dictionary.apa.org/emerging-adulthood

Chan S. L., Hutagalung, F. D., \& Lau P. L. (2017). A Review of Depression and Its Research Studies in Malaysia. International Journal of Education, Psychology and Counseling, 2(4), 40-55.

Fava, G. A., \& Ruini, C. (2003). Development and characteristics of a well-being enhancing psychotherapeutic strategy: Well-being therapy. Journal of Behavior Therapy and Experimental Psychiatry, 34, 45-63. https://doi.org/10.1016/S0005-7916(03)00019-3

Fredrickson, B. L., \& Joiner, T. (2002). Positive emotions trigger upward spirals toward emotional wellbeing. Psychological Science, 13, 172-175. https://doi.org/10.1111/1467-9280.00431

Gillian, S. J. (2019). Rethinking how we heal from anxiety and depression. Retrieved from https://www.psychologytoday.com/us/blog/think-act-be/201902/rethinking-how-we-heal-anxiety-anddepression

Hanafiah, A. N., \& Bortel, T. Van. (2015). A qualitative exploration of the perspectives of mental health professionals on stigma and discrimination of mental illness in Malaysia. International Journal of Mental Health Systems, 9, 1-12. https://doi.org/10.1186/s13033-015-0002-1

Hernáez, A. M., Maicas, N. C., Digiacomo, S. M., \& Ariste, S. (2016). Social support and gender differences in coping with depression among emerging adults: a mixed-methods study. Child and Adolescent Psychiatry and Mental Health, 10, 1-11. https://doi.org/10.1186/s13034-015-0088-x

Holubova, M., Prasko, J., Ociskova, M., Grambal, A., Slepecky, M., Marackova, M., ... \& Zatkova, M. (2018). Quality of life and coping strategies of outpatients with a depressive disorder in maintenance therapy-a cross-sectional study. Neuropsychiatric Disease and Treatment, 14, 73-82. https://doi.org/10.2147/NDT.S153115

Kern, M. \& Khaw, D. (2015). A Cross-Cultural Comparison of the PERMA Model of Well-Being. Undergraduate Journal of Psychology at Berkeley, 8(1), 10-23.

Kopala-Sibley, D. C., \& Zuroff, D. C. (2020). The self and depression: Four psychological theories and their potential neural correlates. Journal of Personality, 88(1), 14-30. https://doi.org/10.1111/jopy.12456

Ledwidge, B. (1980). Run for your mind: Aerobic exercise as a means of alleviating anxiety and depression. Canadian Journal of Behavioural Science, 12(2), 126-140. https://doi.org/10.1037/h0081048

Nowell, L. S., Norris, J. M., White, D. E., \& Moules, N. J. (2017). Thematic Analysis: Striving to Meet the Trustworthiness Criteria. International Journal of Qualitative Methods, 16(1), 1-13. https://doi.org/10.1177/1609406917733847 
Pascha, M. (2019). The PERMA model: Your scientific theory of happiness. Retrieved from https://positivepsychology.com/perma-model/

Pieters, H. C., \& Heilemann, M. V. (2010). "I can't do it on my own": Motivation to enter therapy for depression among low income, second-generation Latinas. Issues in Mental Health Nursing, 31(4), 279287. https://doi.org/10.3109/01612840903308549

Rajendran, N. (2001). Dealing With Biases in Qualitative Research: A Balancing Act for Researchers. In a poster presented at Qualitative Research Convention.

Rottenberg, J., Devendorf, A. R., Panaite, V., Disabato, D. J., \& Kashdan, T. B. (2019). Optimal WellBeing After Major Depression. Clinical Psychological Science, 7(3), 621-627. https://doi.org/10.1177/2167702618812708

Santos, V., Paes, F., Pereira, V., Arias-carrión, O., Silva, A. C., Carta, M. G., \& Machado, S. (2013). The Role of Positive Emotion and Contributions of Positive Psychology in Depression Treatment: Systematic Review. Clinical Practice and Epidemiology in Mental Health, 9 (1), 221-237.

Schrank, B., Brownell, T., Tylee, A., \& Slade, M. (2014). Positive psychology: An approach to supporting recovery in mental illness. East Asian Archives of Psychiatry, 24(3), 95-103.

Shumye, S., Belayneh, Z., \& Mengistu, N. (2019). Health-related quality of life and its correlates among people with depression attending outpatient department in Ethiopia: a cross-sectional study. Health and Quality of Life Outcomes, 17(1), 1-9. https://doi.org/10.1186/s12955-019-1233-7

Sin, N. L., Della Porta, M. D., \& Lyubomirsky, S. O. N. J. A. (2011). Tailoring positive psychology interventions to treat depressed individuals. Applied positive psychology: Improving everyday life, health, schools, work, and society, 79 -96. New York, NY: Routledge.

Teo, K., \& Say, Y. (2012). Prevalence of Depression and Cognitive Distortion among a Cohort of Malaysian Tertiary Students. Research in Neuroscience, 1(1), 1-7. https://doi.org/10.5923/j.neuroscience.20120101.01

Van Grieken, R. A., Kirkenier, A. C., Koeter, M. W., \& Schene, A. H. (2014). Helpful self-management strategies to cope with enduring depression from the patients' point of view: a concept map study. BMC Psychiatry, 14(1), 1-9. https://doi.org/10.1186/s12888-014-0331-7

Version, D., \& Rights, P. (2012). Immobility, Battles, and the Journey of Feeling Alive: Women's Metaphors of Self-Transformation Through Depression and Recovery. Qualitative Health Research, 22(8), 1063-1072. https://doi.org/10.1177/1049732312443738

Yeap, R., \& Low, W. Y. (2009). Mental health knowledge, attitude, and help-seeking tendency: a Malaysian context. Singapore Medical Journal, 50(12), 1169-1176. 